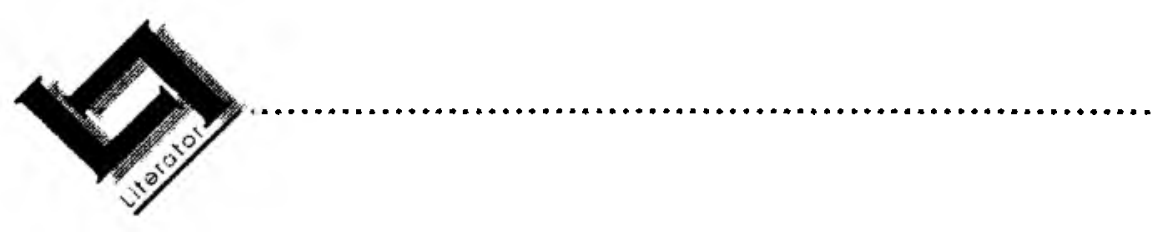

\title{
Oosgrensafrikaans as teoretiese konstruk onder die loep
}

\author{
H.P. Grebe \\ Departement Afrikaans \\ Universiteit van Pretoria \\ PRETORIA \\ E-pos: grebe@libarts.up.ac.za
}

\begin{abstract}
Eastern Cape Afrikaans (Oosgrensafrikaans) theoretically evaluated

Based upon linguistic and geographical considerations the historiography of Afrikaans distinguishes between three early historic varieties. Apart from the two contact varieties, Cape Afrikaans (Kaapse Afrikaans) and Orange River Afrikaans (Oranjerivierafrikaans), Eastern Cape Afrikaans is considered to be primarily a continuous development of seventeenth-century Dutch and constitutes the dialectic basis of Standard Afrikaans.

As such, Eastern Cape Afrikaans has acquired a central position as theoretical concept within the historiography of Afrikaans. The use of such a term presupposes the existence of a fairly homogeneous historic variety which systematically differed from other varieties of Afrikaans. In this article it will be argued that positing Eastern Cape Afrikaans as a separate historic variety has severe theoretical constraints and that such a claim can not - beyond doubt-be established empirically.
\end{abstract}

\section{Inleiding}

Op grond van linguisties-geografiese gronde word daar in die historiografie van Afrikaans (Van Rensburg, 1984:514; 1989:436-467 en 1990:66-67) tussen drie historiese variëteite van Afrikaans onderskei. Afgesien van die twee kontakvariëteite, Kaapse Afrikaans en Oranjerivierafrikaans wat teruggaan op vreemdetaalverwerwing, word die voortsettingsvariëteit, Oosgrensafrikaans, ook onderskei. Volgens Van Rensburg (1984:514; 1989:436-467 en 1990:66-67) het Oosgrensafrikaans ontwikkel uit niestandaardvorme van Nederlands wat gepraat 
is deur die vryburgers en veeboere aan die vroeë Kaap wat later die binneland ingetrek het. Hierdie variëteit het as taalvorm vir 'n kort periode aan die Oosgrens van die vroeë negentiende eeu gestabiliseer en is die binneland in versprei. Ook ander taalkundiges soos Ponelis (1987:9) en Du Plessis (1987a:108 e.v. en 1987b:152 e.v.) onderskrywe in breë trekke so 'n historiese dialekverdeling vir Afrikaans.

Oosgrensafrikaans word verder beskou (Van Rensburg 1989; 1990 \& 1997) as die brondialek van Standaardafrikaans. As sodanig beklee dit as teoretiese begrip 'n belangrike posisie binne die Afrikaanse historiografie. Ongelukkig word die bestaan van Oosgrensafrikaans as unieke variëteit van Afrikaans - en te onderskei van die taalgebruik van hoofsaaklik die burgerbevolking buite die destydse Oosgrens - linguisties nie oortuigend aangetoon nie. Kwalitatiewe en kwantitatiewe linguistiese verskille moet oortuigend bewys word alvorens die bestaan van 'n onderskeie variëteit soos Oosgrensafrikaans as voldonge feit aanvaar kan word. Hierin slaag Van Rensburg en andere myns insiens nie.

Daar word nie oortuigend aangetoon dat sekere kenmerke net in Oosgrensafrikaans voorgekom het nie; en ook nie dat die saambundeling van kenmerke uniek was nie. Ook kwantitatief word Oosgrensafrikaans nie uniek gedefinieer nie - die frekwensie van linguistiese variante word nie as statisties beduidend uitgewys nie.

\section{Die definiëringsprobleem}

Inligting oor die linguistiese kenmerke van spesifiek Oosgrensafrikaans is skraps. Dit kan gelukkig aangevul word op grond van wat in die tersaaklike literatuur oor twee ander vroeë variëteite van Afrikaans, naamlik negentiende-eeuse Transvaalse Afrikaans en Van der Merwe-Afrikaans, bekend is.

Van Rensburg en Combrink (1984:107-133) bespreek negentiende-eeuse Transvaalse Afrikaans taamlik uitvoerig aan die hand van berigte in vroeë Transvaalse koerante. Aan die hand hiervan trek hulle dan bepaalde konklusies oor die gesproke karakter daarvan. Vroeë Transvaalse Afrikaans kan met 'n redelike mate van sekerheid as verteenwoordigend van Oosgrensafrikaans gereken word omdat bykans almal wat iets daaroor gepubliseer het, daarvan melding maak dat Oosgrensafrikaans deur die Groot Trek die binneland in versprei is en dat Transvaalse Afrikaans 'n direkte voortsetting daarvan is. Van Rensburg (1989: 448) beweer byvoorbeeld: "Vroeë Transvaalse Afrikaans word gekarakteriseer deur dieselfde verskynsels wat Oosgrens-Afrikaans tipeer".

'n Ander bron vir die beskrywing van Oosgrensafrikaans is die sogenaamde Van der Merwe-Afrikaans (VDMA) soos beskrywe deur Du Plessis (1987a \& 1987b). Van hierdie variëteit van Afrikaans beweer Du Plessis (1987b): 
Daar bestaan vanuit fonologiese kant oorweldigende getuienis dat VDMA nie bloot ' $n$ vorm van hedendaagse SA is nie, maar eerder beskou moet word as 'n merkwaardig presiese (sic) gepreserveerde vorm van die Voortrekker-Afrikaans van die einde van die vorige eeu (p. 149);

en

[o]p grond van die analise van hierdie chronolek kan mens met effens meer selfvertroue 'n oordeel uitspreek en dit kan ook 'n basis vorm op grond waarvan die driedeling van Transvaalse (lees: Oosgrensafrikaans - HPG), Kaapse en Oranjerivier-Afrikaans verder in die geskiedenis van Afrikaans teruggevoer kan word (p. 160).

Du Plessis (1987b) wys ook daarop dat Van der Merwe-Afrikaans sedert 1880 "weinig tekens van ontwikkeling" (p. 123) vertoon en daarom as 'n Afrikaanse chronolek (p. 120) beskou kan word wat "op meer as een vlak 'n bydrae kon lewer tot die beskrywing van hedendaagse Standaard-Afrikaans en die ontwikkeling daarvan" (p. 121). Op grond van wat oor Vroeë Transvaalse Afrikaans en Van der Merwe-Afrikaans bekend is, kan 'n lys onderskeidende kenmerke van Oosgrensafrikaans gekonstrueer word. Vir nadere besonderhede word die leser verwys na Grebe (1997:147 e.v.). Voordat die lyste kenmerke waarna hierbo verwys is, vanuit taalvariasionele oogpunt teoreties bespreek word, is enkele algemene opmerkinge tog noodsaaklik.

- Ten eerste is dit belangrik om daarop te let dat Oosgrensafrikaans juis tiperend gedefinieer word in terme daarvan asof Standaardafrikaans hoofsaaklik daarop gegrondves sou wees. Dit lei noodwendig daartoe dat in vele gevalle bepaalde kenmerke wat as tiperend van Oosgrensafrikaans aangebied word, as 't ware by voorbaat van hul krag as onderskeidende kenmerke ontdaan word omdat hulle vanweë hul voorkoms in Standaardafrikaans algemene Afrikaanse kenmerke verteenwoordig - vergelyk in hierdie verband die gegewe dat Oosgrensafrikaans gekenmerk is deur $t$-lose vorme na stemlose konsonante.

- Ten tweede word dikwels melding daarvan gemaak dat Oosgrensafrikaans in vele gevalle "niestandaardvorme van Nederlands" voortgesit het. Deur die standaardiseringsproses van Afrikaans wat reeds teen die einde van die vorige eeu begin het (Raidt, s.j.:200 e.v.; vergelyk in hierdie verband ook die eerste spelbeginsels soos deur die GRA uitgegee), is talle van hierdie kenmerke uit Standaardafrikaans geweer, onder andere as gevolg van die sogenaamde Nederlandse normeringsoorweging. Dit bly onseker in welke mate kenmerke wat as tiperend aangedui word van die Oosgrensafrikaans van die middel van die vorige eeu, en tans nie in die standaardtaal of ander variëteite voorkom nie, nie gewoon verteenwoordigend van sulke niestandaardvorme was nie. 
Inmiddels kon die standaardtaal dit oor 'n breë front teruggedring het, of kon dit heeltemal verdwyn het.

- Ten derde is daar die probleem dat die status van sekere kenmerke as tiperend van Oosgrensafrikaans histories op betreklik wankelrige gronde berus. Ponelis

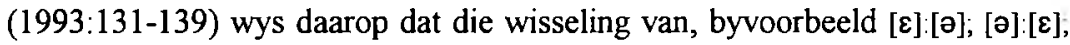
[u]:[0]; [0]:[œ]; en [œy]:[ø], baie ou verskynsels is en dat dit teruggaan op Middelnederlands en selfs verder. Juis hierom kom dit dan in ander variëteite van Afrikaans as net in Oosgrensafrikaans ook voor. Dit beteken natuurlik dat die voorkoms van variante in Oosgrensafrikaans wat met hierdie wisselinge verband hou, Oosgrensafrikaans geensins as unieke variêteit van Afrikaans karakteriseer nie.

Ernstiger tekortkominge kan egter vanuit 'n teoretiese oogpunt uitgewys word teen die karakterisering van Oosgrensafrikaans op grond van gewoon 'n lys kenmerke, soos inderdaad in die onderhawige literatuur die geval is. Vervolgens sal aangetoon word dat die begrip "Oosgrensafrikaans" soos wat dit tans geformuleer is, geensins daarop aanspraak kan maak om meer te wees as 'n preteoretiese werkshipotese nie.

\subsection{Sistematiese onderskeidenheid}

As met die begrippe "variëteit" en "dialek" omgegaan word, is die kwessie van taalverskeidenheid vanselfsprekend ter sake. In hierdie verband is dit belangrik dat duidelikheid verkry word oor enkele begrippe.

- Webb (1989:416-417) definieer 'n veranderlike as 'n entiteit wat meer as een waarde of realisasievorm kan hê. "Geslag" kan byvoorbeeld 'n veranderlike wees omdat dit of na manlik, of na vroulik kan verwys. 'n Verdere voorbeeld van ' $n$ veranderlike is byvoorbeeld fonetiese veranderlikes. Webb gee die voorbeeld van die verkleiningsmerker in Afrikaans wat as óf [ci], of [t $\mathrm{i}$ i] uitgespreek kan word. Sulke verskillende realisasievorme van 'n veranderlike heet variante.

- Die begrip "variêteit" word in die literatuur (Du Plessis, 1987b:9, asook Hudson, 1982:24) gedefinieer as enige vorm van 'n bepaalde taal wat sistematies op meer as een analisevlak van 'n ander vorm van dieselfde taal te onderskei en in verband te bring is met ooreenstemmende sosiale en/of geografiese verspreiding. Die term variëteit word gewoonlik as sambreelterm gebruik en slaan op 'n bepaalde patroonmatige sisteem van linguistiese eienskappe met 'n aantoonbare sosiale en/of geografiese verspreiding. Webb (1989: 416) stel dit soos volg: "'n Variëteit van 'n taal kom tot stand wanneer 'n aantal variante gesamentlik geassosieer raak met 'n bepaalde groep mense, 'n bepaalde situasie of ' $n$ bepaalde aktiwiteit'. 
So gesien, kan die term onder bepaalde omstandighede verwys na 'n taal self, 'n dialek, en 'n bepaalde styl of register. Hieruit kan dus onmiddellik afgelei word dat dit nie genoeg is om 'n variëteit soos Oosgrensafrikaans bloot in terme van 'n lys kenmerke te definieer nie.

In die eerste plek moet aangetoon kan word dat bepaalde kenmerke hoofsaaklik in Oosgrensafrikaans voorgekom het. Dit word volgens 'n studie van tersaaklike literatuur nêrens gedoen nie. Tweedens is dit nie genoeg om gewoon net aan te dui dat ' $n$ veranderlike in ' $n$ bepaalde variëteit voorkom nie. Dit is ook nodig om aan te toon dat die voorkomsfrekwensie van hierdie kenmerk beduidend verskil het van diè in ander vorme van vroeë Afrikaans, of dat die korrelasie tussen die voorkoms van die kenmerk en die bepalende sosiale en ander faktore anders uiteenval. ${ }^{1}$ In hierdie verband is die werk van Trudgill (1983); Trudgill en Chambers (1991) en Webb (1984a en 1984b) veral ter sake. Soos hieronder vlugtig aangetoon word, kry die voorkomsfrekwensie van variante en die korrelasie tussen variante en bepalende faktore in baie van die tersaaklike literatuur oor Oosgrensafrikaans glad nie aandag nie, of word dit nie ernstig genoeg opgeneem nie.

Deur te beweer (Du Plessis, 1987b:125-160) dat 'n bepaalde veranderlike "'n hoë gebruiksfrekwensie het" of "selde voorkom" of "algemener" of "beperkter as in Standaardafrikaans" voorkom, is nie voldoende nie. Billikheidshalwe moet vermeld word dat $\mathrm{Du}$ Plessis hom nie onbewus is van die belang van frekwensiestudies nie. In sy bespreking van Van der Merwe-Afrikaans (Du Plessis, 1987b:110) meld hy wel dat kontroleopnames op vyftien plekke dwarsoor die land gemaak is wat nie in "dieselfde besonderhede verwerk is" as in die geval van die Van der Merwe-Afrikaans nie. Frekwensieverskille in die voorkoms van bepaalde veranderlikes was dan deurslaggewend in die kenmerkbeskrywing van Van der Merwe-Afrikaans. Ongelukkig word geen verdere besonderhede oor hierdie frekwensieverskille verskaf nie. As Du Plessis (1987b: $137 \& 138$ ) dus van nasaalassimilasie beweer: "Nasaalassimilasie kom baie dikwels in Standaard-Afrikaans voor [...]. Nasaalassimilasie kom selde in VDMA voor. [...]. Hierdie afwesigheid kan as 'n kenmerk van VDMA beskou word", sou verwag word dat dit deur 'n frekwensie-indeks van die een of ander aard ondersteun sal word; daarsonder kan dit hoogstens as ' $n$ preteoretiese werkshipotese opgevat word. As sodanig is dit vanselfsprekend nouliks toetsbaar.

1 Die uitgebreide databronne wat deur Raidt en Scholtz bestudeer is, sal in hierdie verband nuttig kon wees, maar sal eers geherinterpreteer moet word 
Verwysend na die onderskeid tussen variëteite as gebaseer op 'n skaal van variasie, en die onderskeid wat Van Rensburg tref tussen die drie historiese variëteite van Afrikaans, sê Du Plessis (1987b:12):

Die onderskeid wat Van Rensburg (1984) tref tussen Transvaalse (of Oosgrens-), Kaapse en Oranjerivier-Afrikaans bly op so 'n skaalvoorstelling geldig, maar ook die subvariêteite van hierdie drie basiese vorme sou op dieselfde klien tereg kon kom. Dit is immers so dat nie een van hierdie drie 'n inherente heterogeniteit veronderstel nie.

Hieruit kan dus afgelei word dat ook Du Plessis die siening onderskrywe dat variëteite primêr kwantitatief, en nie noodwendig kwalitatief nie, van mekaar verskil. Hy gaan verder (Du Plessis 1987b:11) en stel dit onomwonde dat variëteite heel dikwels van mekaar verskil bloot op grond van die voorkomsfrekwensie van die variante en nie gewoon op grond van die aan- of afwesigheid van 'n verskynsel wat 'n variëteit as variëteit merk nie. Hierooreenkomstig kan 'n variëteit dus beskou word as 'n gradering op 'n variasieklien van dieselfde taal. Du Plessis (1987b:11) stel dit so: "Die standaardtaal sou dan op die bopunt van die skaal die boonste limiet van die klien vorm, terwyl ... geografiese dialek[te] die onderpunt daarvan vorm." Om een variëteit van 'n ander te onderskei, is dit dus ook volgens hom nie genoegsaam om gewoon 'n inventaris van onderskeidende kenmerke aan te bied nie.

In hierdie verband wys Cheshire (1982:26) daarop dat binne 'n sosiolinguistiese benadering tot taalvariasie veral twee belangrike stadia onderskei behoort te word. Die eerste stap hou in dat die linguistiese veranderlikes (d.i. die onderskeidende kenmerke van Oosgrensafrikaans wat in die literatuur vermeld word) op die verskillende analisevlakke geïnventariseer moet word. Verder wys sy dan ook daarop dat sekere veranderlike verskynsels wat wel in die data mag voorkom, nie noodwendig bruikbaar is nie omdat die voorkomsfrekwensie daarvan gewoon nie statisties beduidend mag wees nie. Hierdie geldigheidsfaktor waaraan kenmerke moet voldoen, kom nêrens in die literatuur oor Oosgrensafrikaans aan bod nie.

As tweede stap vermeld Cheshire (1982:26) dat die kwantifisering van die data binne die Laboviaanse raamwerk 'n voorvereiste is voordat enigsins tussen variëteite onderskei kan word. Webb (1989:418) omskrywe die taak van die variasietaalkundige verwysend na hierdie kwantifiseringseis binne Laboviaanse raamwerk baie duidelik as hy die volgende beweer: "Die variasietaalkundige ... moet die groot hoeveelheid variasie wat daar in menslike tale voorkom, ondersoek met die doel om vas te stel of daar sisteem, patroon onderliggend daaraan is, en of dit chaoties en arbitrêr is." Dit hou in dat die taalkundige die waarskynlikheid dat 'n bepaalde variant van 'n gegewe veranderlike sal voorkom, kwantitatief moet kan uitdruk. 
Verder is dit belangrik om in hierdie verband te beklemtoon dat die onderskeid tussen variëteite dikwels nie kwalitatief is nie, maar kwantitatief. Al kan 'n bepaalde variëteit soms op grond van die voorkoms van 'n bepaalde kenmerk van ' $n$ ander onderskei word indien dit by die een aanwesig is en by die ander nie, is dit egter nie altyd so eenvoudig nie. Soms is dit veel eerder 'n kwessie van graadverskil. So kan die voorkomsfrekwensie van 'n bepaalde kenmerk by een variëteit veel hoër wees as by 'n ander, en juis hierdie kwantitatiewe verskil kan ten grondslag lê aan die onderskeid tussen die variëteite. Dieselfde kenmerk kan ook by meer as een variëteit voorkom, maar juis die kombinasie van daardie kenmerk saam met ander kenmerke kan twee varietëite van mekaar onderskei.

Aan die bovermelde aspekte van verskil tussen variëteite word geen aandag geskenk in die literatuur oor Oosgrensafrikaans nie.

\subsection{Oorbeklemtoning van die geografiese faktor}

Soos oorsigtelik uiteengesit, onderskei Van Rensburg tussen Kaapse Afrikaans en Oranjerivierafrikaans enersyds, en Oosgrensafrikaans andersyds op grond van histories-etniese redes. Voorts word Oosgrensafrikaans ook geografies afgebaken.

Teenoor die twee kontakvariëteite van Afrikaans, Kaapse Afrikaans en Oranjerivierafrikaans, stel Van Rensburg Oosgrensafrikaans. Hierdie variëteit het volgens hom gegroei uit die taal van landelike burgers wat van die Kaap die binneland ingetrek het. Hoewel Van Rijn (1914:16) heel eksplisiet op grond van sosio-etniese faktore onderskei as hy Kleurlinghollands teenoor Burger- en Boerehollands stel, gee Van Rensburg egter met die benaming Oosgrensafrikaans myns insiens eksplisiet te kenne dat die dialek/variëteit pertinent op grond van histories-geografiese gronde onderskei word en dat Oosgrensafrikaans in wese 'n geografiese dialek was.

Dit is wél so dat Van Rensburg die taal van die vryburgers en die veeboere sien as die grondslag van Oosgrensafrikaans, maar teen die einde van die agtiende eeu situeer hy die voortsetting daarvan geografies "aan die ooskus van Suid-Afrika" (Van Rensburg, 1997:31). Hieruit sou dan afgelei kan word dat Oosgrensafrikaans te onderskei is van die Afrikaans wat deur die burgerboerebevolking buite die negentiende-eeuse Oosgrens gepraat is.

Een van die vernaamste besware wat teen so 'n dialekgeografiese siening ingebring kan word, sluit direk aan by die beswaar wat hierbo geopper is in verband met die gebrek aan kwantifisering. Veral binne die meer moderne variasietaalkundige benadering (vgl. Trudgill \& Chambers, 1991) word daarop gewys dat die oorbeklemtoning van die geografiese faktor die werklike dinamiek wat variasie onderlê, mag negeer. 
Soos hierbo reeds aangedui, word Oosgrensafrikaans in die tersaaklike literatuur (Van Rensburg, 1984:514; 1989:436-467; 1990:66-67 \& 1997:31) hoofsaaklik as 'n histories-geografiese variëteit gedefinieer. Miskien juis as gevolg hiervan is daar volstaan met die inventarisering van 'n stel identifiserende kenmerke. As taalvariasie meer vanuit die standpunt van Labov se sosiolinguistiese benadering beskou is, sou dit gewoon onmoontlik gewees het om met 'n lys kenmerke te volstaan sonder om dit te kwantifiseer en in verband te bring met ander sosiale faktore.

Hierdie punt van kritiek ontken nie die geografiese as 'n moontlike faktor ten opsigte van historiese variasie in Afrikaans nie. Dit is egter sonder tywfel waar dat 'n preteoretiese hipotese sonder die nodige empiriese ondersteuning nie tot feit verhef kan word nie.

Teenoor hierdie histories-geografiese siening van variasie in vroee Afrikaans is daar 'n ander moontlikheid, naamlik dat eerder in terme van 'n sosiolek gedink moet word. Was Oosgrensafrikaans nie allig 'n dialek wat gepraat is deur hoofsaaklik die burgerbevolking en ander lede van dieselfde spraakgemeenskap van oorkant die eerste Kaapse bergreekse tot aan die negentiende-eeuse Oosgrens nie? So 'n siening verskil natuurlik nie wesenlik van die siening van Van Rensburg dat Afrikaans in die agtiende eeu in drie verskillende soorte Afrikaans uiteengeval het nie. Dit verskil egter wel wesenlik wat betref die definiëring van wat Van Rensburg as Oosgrensafrikaans beskou. In die lig hiervan sou 'n benaming soos Burgerafrikaans (wat dui op die taal van die burgertrekboere van die sewentiende en vroeë agtiende eeu) stellig meer gepas wees.

In hoe ' $n$ mate die taal van die burgerboerebevolking in die bakermat van die Kaap hierby aansluiting gevind het, is steeds onduidelik. De Villiers en Ponelis (1987:45) meen tog dat tiperende kenmerke van hedendaagse Kaapse Vernakular-Afrikaans voorheen algemener in die taal van 'n groter verskeidenheid sprekers van die Kaap en omstreke voorgekom het

\section{Gevolgtrekking}

Die bestaan van Oosgrensafrikaans as unieke variëteit van Afrikaans as te onderskei van die taalgebruik van hoofsaaklik die burgerbevolking buite die destydse Oosgrens is in die tersaaklike navorsing linguisties nie oortuigend aangetoon nie. Kwalitatiewe en kwantitatiewe linguistiese verskille moet oortuigend bewys kan word voordat die bestaan van 'n onderskeie variëteit soos Oosgrensafrikaans as voldonge feit aanvaar mag word.

Hierin slaag Van Rensburg en andere myns insiens nie. Hulle slaag nie daarin om Oosgrensafrikaans as linguisties onderskeie van die spraak van ander burgers en medetaalgenote elders in die destydse Kolonie te tipeer nie. Daar is hoogstens 
gesuggereer dat die taal van 'n deel van die burgerbevolking moet verskil het van die taal van die slawe, die Koikoi en hul nakomelinge (d.i. Kaapse Afrikaans en Oranjerivierafrikaans) aan die verste uithoeke van die Kolonie.

Daar word nie oortuigend aangetoon dat sekere kenmerke net in Oosgrensafrikaans voorgekom het nie; en ook nie dat die saambundeling van kenmerke uniek was nie. Ook kwantitatief word Oosgrensafrikaans nie uniek gedefinieer nie - die frekwensie van linguistiese variante word nie as statisties beduidend uitgewys nie

Oosgrensafrikaans word dus geensins op grond van linguistiese kenmerke oortuigend getipeer as te onderskei van die spraak van ander burgers nie.

Voorts, deur Oosgrensafrikaans geografies en ook etnies as 'n linguisties onderskeibare variëteit van Afrikaans te beskou en dit dan terselfdertyd as die basisdialek van moderne Standaardafrikaans te sien, word die geskiedenis van moderne Standaardafrikaans nie alleen in linguistiese terme opnuut gepolitiseer nie, maar word die rol wat van vroeë intertaalvariëteite moet uitgegaan het, nie op geīntegreerde wyse verantwoord nie. Die onderskeie "kragte" wat daar van sowel die aanleerders- as voortsettingsvariëteite uitgegaan het, en hoe hierdie "kragte" saamgesnoer is tot Afrikaans, moet aangetoon word.

\section{Vooruitskouend}

Die onsekerhede rondom die status van Oosgrensafrikaans as onderskeibare historiese variëteit van Afrikaans, en veral ten opsigte van sy posisie in verhouding tot moderne Standaardafrikaans, bring opnuut ander belangrike vraagstukke na vore:

- Is dit werklik nodig om ooreenkomstig sterk etnies-geografiese afgrensinge te dink om tot belangrike insigte oor die geskiedenis van Standaardafrikaans te kom?

- Etniese faktore moet waarskynlik wel 'n rol gespeel het, maar of dit noodwendig daartoe gelei het dat Oosgrensafrikaans tot afsonderlik onderskeibare voortsettingsvariëteit ontwikkel het, is onseker.

- Die moontlikheid van 'n variasiekontinuum met 'n voortsettingsvariëteit en aanleerdersvariëteite aan die uiterste punte daarvan mag insiggewender blyk te wees.

Immers, die variëteite Kaapse Afrikaans en Oranjerivierafrikaans word in terme van die intertaalteorie gedefinieer, en so 'n teorie het as een van sy basiese aksiomas die bestaan van ' $n$ intertaalkontinuum. Die verskillende stadia op 
hierdie kontinuum sou uiteraard 'n baie oop sisteem verteenwoordig het. Roberge $(1995: 77,82)$ onderskrywe hierdie moontlikheid:

... [interlanguages] neither shared norms nor stability in given individuals. In fact, an interlanguage continuum in the Cape Colony between 1652 and 1700 could have ranged from the most rudimentary jargon to fluent, nonnative Dutch[.];

... the Dutch language at the Cape of Good Hope formed a continuum from the most creole-like variety within the Afro-Asian substrate to an uncreolised extra-territorial variety of the European superstrata.

Die onderskeie "kragte" wat daar van sowel die aanleerders-, as voortsettingsvariëteite uitgegaan het, en hoe hierdie "kragte" saamgesnoer is tot Afrikaans, moet aangetoon word. Eerder dus as om Standaardafrikaans te sien as die voortsetting van primêr 'n voortsettingsvariëteit soos Oosgrensafrikaans, kan dit vrugbaar wees om, soos Roberge, in terme van 'n oop sisteem te dink met voortsettings- en aanleerdersvorme as benaderde punte op 'n taalkontinuum.

\section{Bronverwysings}

Cheshire, J. 1982. Variation in an English dialect. Cambridge : Cambridge University Press.

De Villiers, M. \& Ponelis, F A. 1987. Afrikaanse klankleer. Kaapstad : Tafelberg.

Du Plessis, H. 1987a. Aspekte van Suidwes-Afrikaans met spesifieke verwysing na die Afrikaans van die Van der Merwes. Pretoria : RGN-verslag.

Du Plessis, H. 1987b. Variasietaallunde. Pretoria : Serva

Grebe, H.P. 1997. Die historiografie van Afrikaans in heroēnskou. Pretoria : Universiteit van Pretoria. (D.Litt -proefskrif.)

Hudson, R.A. 1982. Sociolinguistics. Cambridge : Cambridge University Press.

Ponelis, F.A. 1987. Die eenheid van die Afrikaanse taalgemeenskap. In: Du Plessis, H. \& Du Plessis, T (reds.) Afrikaans en taalpolitiek. Pretoria : HAUM p. 3-15.

Ponelis, F.A. 1993. The development of Afrikaans. Frankfurt am Main : Peter Lang.

Raidt, E.H. s j. Afrikaans en sy Europese verlede. Tweede druk. Kaapstad : Nasou

Roberge, Paul T. 1995. The formation of Afrikaans In: Mesthrie, R. Language and social history: studies in South African socio-linguistics. Cape Town : David Philip. p 68-87.

Trudgill, P. 1983. On dialect: a social and geographical perspective. Oxford : Blackwell.

Trudgill, P. \& Chambers, J.K 1991. Dialects of English: studies in grammatical variation. London : Longman.

Van Rensburg, M.C.J. 1984 Die Afrikaans van Griekwas in die tagtigerjare. Pretoria : RGNverslag.

Van Rensburg, M.C.J 1989. Soorte Afrikaans. In: Botha, T J.R (red.) Afrikaanse sintaksis. Pretoria : Academica. p. 436-467.

Van Rensburg, M.C.J 1990. Taalvarieteite en die wording van Afrikaans in Afrika. Bloemfontein : Patmos

Van Rensburg, M.C.J. (red.) 1997. Afrikaans in Afrika. Pretoria : Van Schaik.

Van Rensburg, M.C.J \& Combrink, J.H. 1984. Transvaalse Afrikaans. In: Botha, T J.R (red.) Afrikaanse sintaksis. Pretoria: Academica. p. 107-133.

Van Rijn, C.J. 1914. Het zeer nawwe verband tussen het Afrikaans en het Nederlands. Kaapstad : deur skrywer self uitgegee. 
Webb, V.N. 1984a. Die bestudering van linguistiese heterogeniteit m.b.v. die rekenaar vanuit die perspektief van Labov se kwantitatiewe paradigma. In: Webb, V.N. (red.) LVSAkongresreferate, 20. Pretoria : Universiteit van Pretoria. p. 725-756.

Webb, V.N. 1984b. Sosiolinguistiek en die spraakwetenskap. In: Beukes, S.M. (red.) Die rol van die spraakterapeut in 'n meertalige samelewing. Pretoria : Universiteit van Pretoria. p. 22-37.

Webb, VN. 1989. Die Afrikaanse variasietaalkunde In: Botha, T J.R. (red ) Afrikaanse sintaksis. Pretoria : Academica p 412-435 
